\title{
The COVID-19 Pandemic: a Year Lost, or a Year Found?
}

\author{
Neil Osheroff ${ }^{1,2}$ (1)
}

Accepted: 16 August 2021 / Published online: 26 August 2021

(C) International Association of Medical Science Educators 2021

\begin{abstract}
This commentary is based on the Leadership Plenary at the IAMSE 2021 Virtual Conference and describes the response of the International Association of Medical Science Educators (IAMSE) to the COVID-19 pandemic.
\end{abstract}

Keywords IAMSE · COVID-19 $\cdot$ Pandemic $\cdot$ Member engagement $\cdot$ International footprint $\cdot$ Diversity, equity, and inclusion

\section{A Year Lost}

The previous year has been defined by a series of unprecedented challenges. We have faced the COVID-19 pandemic with all of its associated health demands. We have witnessed the collapse of university and hospital budgets that for many faculty and staff has resulted in the loss of salary, retirement benefits, and/or development funds [1-3]. We also have endured social isolation and travel restrictions [4-8]. Finally, we have dealt with racial and social unrest that started in the United States and spread throughout the world [9]. This unrest was triggered by the killings of George Floyd and Breonna Taylor as well as many other named and unnamed individuals.

It has been a difficult year for all and in many respects, it has been a year lost.

To those who had to switch their curricula from in-person to online within a matter of days, to find novel ways to educate their trainees and stay connected with students and colleagues, and to work many additional hours under stressful conditions, the International Association of Medical Science Educators (IAMSE) acknowledges your hard work and many successes [10-15].

For those who were sick, had sick loved ones, or lost family members or friends, IAMSE is sorry and grieves with you.

Neil Osheroff

neil.osheroff@vanderbilt.edu

1 Departments of Biochemistry and Medicine (Hematology/ Oncology), Vanderbilt University School of Medicine, Nashville, TN 37232, USA

2 VA Tennessee Valley Healthcare System, Nashville, TN 37212, USA
For those who had to continue to work while dealing with their own stresses, healthcare concerns, or isolation from family and friends, or while taking care of loved ones, juggling family day care centers, or at-home schools, IAMSE salutes you and thanks you [4, 16-22].

For those who did these (and so many additional things) with seemingly little or no thanks or for those who received mixed messages about keeping well while constantly being expected to provide more effort, this is a failure of your leaders and administrators. IAMSE appreciates your efforts and recognizes your amazing achievements.

The year has also brought inequities into full view.

COVID-19 has been particularly hard on women, parents, and caregivers [17, 23]. Hearing children in the background or seeing a child on someone's lap during a Zoom call is now recognized as a part of life and reflects the difficulties that have faced many of our colleagues during the pandemic $[18,19]$. Rather than seeing the presence of children as unprofessional or disruptive, we now see happy little faces peeking into Zoom calls as heroic and joyful distractions. Joyful distractions also apply to puppies and cat tails wafting across computer screens.

The year has been especially difficult for our Black, Brown, and Asian colleagues [24-31]. It has made America and the world face the dangers, stresses, and racism that many of our colleagues live with on a daily basis. Antisemitism and anti-Islamic sentiments have risen throughout the world [8, 32-34], and the statistics of COVID-19 have brought into full view the inequities that have been going on for too long in our healthcare systems.

It has been a time for difficult and uncomfortable conversations about how to teach in an unbiased manner and how to apply the concepts of antiracism to our teaching sessions and work environments $[35,36]$. 
It has also been a difficult year for many scientific and educational associations, who have struggled with a loss of membership, decreased revenue streams, and reduced member engagement. We all long for the day that we can gather in person again.

\section{A Year Found}

Despite all the issues that have accompanied COVID-19, the pandemic also has been a year found. It has been a time of great innovation accompanied by the development of new skill sets and best practices. This article will describe how IAMSE found opportunities amid the chaos of the pandemic, stepped out of its comfort zone, and took innovative approaches to expand its programs and strengthen the Association.

Early in the pandemic, the leadership of IAMSE began to strategize about how to best approach the uncertain and rapidly devolving situation. Ultimately, the Association made a bold decision. Rather than lamenting about what IAMSE had lost or might lose in the coming months, we chose to take a different course of action. We decided to look at ourselves and use the pandemic to better define the Association. What spoke to the core of IAMSE? What were the things that were important to the Association and its membership that we needed to continue, improve, or initiate? To help with the process, we established a Strategic Leadership Group (consisting of the current President, President-Elect, and three Past-Presidents) to help navigate the Association through the early and most chaotic stages of the pandemic.

Critical to our success was the fact that IAMSE was (and continues to be) in excellent shape financially. We determined that in a worst case, even with a loss of annual meeting (and potentially other) revenues for 1 or 2 years, the Association would remain solvent. The strong financial reserves of IAMSE were crucial to our overall strategy. They allowed us to take chances and provide additional services to our members. As far as leadership was concerned, retreat was not an option. We never considered cutting member services to conserve funds or enacting strategies that were designed to merely survive COVID-19. In contrast, our focus was always on how to move forward and expand services and engagement in a meaningful, safe, and responsible manner (and it remains so). We felt that the best way to accomplish our objectives was to be bold, take chances (when appropriate), and embrace innovation. Our goal was to position IAMSE to come out stronger on the other side of COVID19. As a result, IAMSE is in better shape today than it was at the beginning of the pandemic and the future of the Association is very bright.

As one measure of success, our membership has grown dramatically since the beginning of COVID-19. In contrast to many organizations who lost members over the course of the pandemic, IAMSE has added nearly 500 members since February 2020. We now stand at nearly 1,900 members (an historic high) who represent 43 countries around the world. (Note that in the two months following the 2021 Virtual Conference, IAMSE membership rose to more than 2,100 members from 53 countries).

To move IAMSE forward during the pandemic, we devised a three-pronged strategy to sustain the trust of the membership and support the Association. We focused on enhancing member support and engagement, increasing the global footprint of IAMSE, and enhancing diversity, equity, and inclusion within IAMSE and in the workplace.

\section{Enhancing Member Support and Engagement}

Once people were sent home from their offices because of COVID-19, we recognized that first and foremost, IAMSE needed to take care of its membership. To overcome the uncertainties, worries, stresses, and isolation that accompanied the early days of the pandemic, we felt that it was critical to keep our members connected and engaged. It was a time when our members needed to be supported, regardless of costs.

One of the first things that we did to support our membership was to institute the IAMSE Café - an online forum where members could gather, stay connected, share concerns, and discuss issues that were important to them. The idea of a Café originated at a meeting of the IAMSE Chairs that took place on March 16, 2020, shortly after most of us had been sent home from our offices. The IAMSE Café was announced to membership 11 days later, and the inaugural session was held the following Tuesday on March 31 with a group of approximately eighty attendees. Originally, the Café was held twice weekly. It eventually transitioned to a weekly, and now biweekly, format and it is still going strong more than a year later.

Throughout the pandemic, IAMSE maintained its grant and scholarship programs. We actually increased the number of faculty educational research grant recipients in 2021 and we have just developed a new curriculum development grant in conjunction with ScholarRx.

The Editor and Editorial Board of Medical Science Educator (the journal of IAMSE) continued to function in a spectacular fashion despite COVID-19. The statistics for the journal have been outstanding and record-breaking numbers of submissions and article downloads were recorded in 2020 and to date in 2021. As a result of the increased submissions, IAMSE and Springer agreed to increase the publication frequency of Medical Science Educator from quarterly to bimonthly starting in January 2021 . We are hoping that the journal will be included in PubMed Central in the near future and envision that Medical Science Educator will transition to a monthly publication schedule within the next year or two.

Because we were aware of the financial hardships that had accompanied the pandemic, we offered our first virtual 
meeting in 2020 at no cost for attendees. In addition, the registration fees for the 2021 annual meeting (also held virtually) were considerably lower than those of most other educational or scientific organizations. The meeting was highly successful, and more than nine hundred faculty, staff, administrators, and students registered for the meeting, representing forty-six states and Washington, DC in the United States and thirty-four countries from six continents.

We maintained our Webcast Audio Seminar Series during COVID-19, and the program has been more popular than ever. We also expanded our manuals program during the pandemic. We have six new manuals under development to accompany the two current manuals that were published under the auspices of Springer. We also expanded our Toolkit program that provides how to information for members. Later this year, we will introduce two new toolkits to accompany our Educator Portfolio Toolkit.

We have redesigned and improved the quality of our Fellowship Program and within the next few months, we will admit our first ever online cohort of new fellows to go along with our in-person cohorts. With the help of colleagues from the Association for Medical Education in Europe (AMEE), IAMSE also is developing an online version of the Essential Skills in Medical Education (ESME) Course. The online Fellowship Program and ESME Course will complement our existing in-person versions and will allow colleagues from around the world who may be unable to attend our annual meeting to participate.

We realized that IAMSE needed to do a better job of onboarding new members, especially with its expanding size. Thus, we have established a new onboarding taskforce to ensure that new members feel welcomed and get the most out of their IAMSE experience.

To do a better job of attracting young members, IAMSE reduced membership fees for all students and trainees (postdocs, residents, jr. doctors, fellows, etc.) to only $\$ 25$ per year. In addition, with the generous financial support of Aquifer, every student who requested a registration fee waiver for the 2021 annual meeting received one. We also have instituted (for the first time) student-specific awards for posters and oral presentations at the meeting.

We just completed an agreement with ScholarRx to bring the meeting of their Medical Student Alliance for Global Education (MeSAGE) group to the IAMSE annual meeting on a biennial basis. This group includes the leadership of at least eight of the largest and most important medical student organizations worldwide. We are very excited about having these student leaders attend the IAMSE meeting and getting to know us.

IAMSE has a long history of reaching out to medical students and encouraging them to join the Association and attend our annual meeting. However, we have done relatively little to engage basic science graduate students and postdoctoral fellows who may be interested in a career in medical science education. Consequently, we initiated the PhD Pipeline Project in 2021. Initially, we reached out to students and fellows through the NIH BEST (Broadening Experience in Scientific Training) programs, the American Physician Scientist Association, and Orpheus (Organization for PhD Education in Biomedicine and Health Sciences in the European System) [37]. The PhD Pipeline Program is in its infancy, but we have already received inquiries from nearly eighty basic science graduate students, postdoctoral fellows, and associated faculty.

To better appreciate how to serve our members, it is critical to understand how we view ourselves. Consequently, in 2020, we initiated and funded a study of professional identity formation among basic science medical educators. Although the subject of professional identity formation has been explored for clinical educators in a number of articles, there is a paucity of literature that investigates identity formation in basic scientist medical educators. The initial project has focused on seven United States medical schools, and we are currently analyzing the data from recorded interviews with more than sixty faculty members. We hope to publish our findings and initiate follow up studies with a broadened selection of schools worldwide in the coming year.

Fifty years after their founding, the Group for Research in Pathology Education (GRIPE) felt that as an organization, it was no longer in a position to continue on its own. Consequently, as of July 1, GRIPE was absorbed into IAMSE. Pathologists have a long and active tradition of teaching sciences to medical trainees, and we are pleased to have the members of GRIPE join our Association. GRIPE also brings to IAMSE a pathology image bank and a question bank that have been important resources for many United States medical schools. We plan to modernize these resources and make them available to the broader global health professions community.

\section{Increasing the Global Footprint of IAMSE}

In February 2020, just before the COVID-19 lockdown, IAMSE held a 1-day conference on Integration in Medical and Health Science Education immediately preceding the Ottawa Conference on Assessment in Kuala Lumpur, Malaysia. This was the first stand-alone conference that IAMSE had ever held outside of our annual meeting. Although the specter of the impending pandemic impacted attendance, the conference was very well received and included registrants from six continents and twenty-one different countries, including twelve countries from Asia and Oceania.

Throughout the pandemic, the leadership of IAMSE has been in close contact with leaders of health professional education associations around the globe, including associations 
in the United States, the United Kingdom, Europe, Mexico, Singapore, Malaysia, and Australia/New Zealand. As a result, our relationships with these associations are stronger than ever. We have shared best practices, helped each other, and established multiple collaborations. We have continued to exhibit and present IAMSE-branded symposia, panel discussions, and workshops at medical education conferences throughout the world (albeit virtually) and we are working with some of these associations to co-brand future meetings.

In early 2020, IAMSE established an Ambassador Program to help recruit new members worldwide, address equity issues, and enhance the global branding of the Association. The Program currently has active Ambassadors in Australia, Estonia, China, the Caribbean, Mexico, and Pakistan, and we are looking forward to expanding the breadth of the program in the future.

To further increase the visibility of IAMSE and help provide faculty development to our colleagues in Asia, we have partnered with the Asia Pacific Biomedical Science Educators Association to establish an Asian version of our Webcast Audio Seminar Series. Seminars are presented in time slots that are conducive with the workday in Asian countries, cover topics of interest to health professional educators in the region, and often include speakers from Asian medical schools. The second series of Asian Webcasts will take place in autumn 2021.

\section{Enhancing Diversity, Equity, and Inclusion within IAMSE and in the Workplace}

I had a humbling and difficult conversation with one of our Black IAMSE members in late 2020. I asked the individual if they attended our annual meetings. I was told that they had attended one meeting but had not felt comfortable. The member agreed that they had learned a lot and that everyone had been very nice to them. However, they felt uncomfortable because they did not see other individuals with whom they felt that they could relate.... no one looked like them.

No one should ever feel uncomfortable, out of place, or unsafe at an IAMSE event. To address this critical issue, IAMSE has instituted a number of programs to promote diversity, equity, and the inclusion of Black members and individuals from other marginalized groups.

In June 2020, the President and Board of Directors of IAMSE distributed a strong statement condemning racism, hatred, injustice, and xenophobia in all forms, declaring them antithetical to the roles of educators and academic leaders [38]. The message expressed the deep commitment of IAMSE to social justice and equality for all racial, ethnic, and religious groups across the globe, along with our pledge to work toward a more just, equitable, and inclusive society. As part of this pledge, IAMSE is arranging to provide antiracist training for all of its leaders, board members, and committee chairs.

IAMSE established the EnGAGE (Encouraging Growth and Advocacy in Gaining Equity) Committee to tackle equity issues in IAMSE and in the workplace. This committee is addressing a broad variety of equity issues, including gender, religion, race, inclusivity, and others.

IAMSE developed a Racial Equity Initiative under the umbrella of the EnGAGE Committee. This group is establishing a Community of Practice for Faculty of Color. It is our hope that this Community of Practice will constitute a safe space for individuals to network, learn, seek advice, and begin to become involved in IAMSE. It will be especially important for members who are unable to attend our annual meeting.

We have reached out to the four Historically Black Medical Schools in the United Sates and have arranged for institutional IAMSE memberships for their faculty and students. We also have provided an institutional membership for University of Liberia A.M. Dogliotti College of Medicine, which is the only medical school in a post-conflict country. IAMSE is in the process of reaching out to other medical schools that serve underrepresented and marginalized populations, including indigenous peoples.

As discussed earlier, IAMSE is establishing online versions of the ESME Course and our Fellowship Program. We believe that this addresses an important equity issue, as it will allow individuals (especially our international colleagues) to have access to the Course and Program, even if they cannot afford to travel to our annual in-person meeting.

Lastly, we have worked with the Physician Assistant Education Association (PAEA), to establish the IAMSE-PAEA Scholars Program. The leaders of both Associations are extremely proud of this Program, which will target faculty from minority institutions. The first cohort of Scholars will come from physician assistant programs at five historically Black Universities in the United States. IAMSE is providing institutional memberships and Webcast Audio Seminar subscriptions for these programs. In addition, two faculty members from each university will attend our ESME Course, Fellowship Program, and at least two annual IAMSE meetings. Our goal is to create a nucleus of educational leaders at each institution who will help to improve training of their learners, so that they can better serve underrepresented and marginalized patient populations. This partnership between IAMSE and PAEA represents a model that can be applied to a variety of programs in the United States and worldwide. We are already discussing possible second cohorts with PAEA. The IAMSE-PAEA Scholars Program has the potential to become an important and impactful program. 


\section{Summary}

The challenges of the COVID-19 pandemic have been many. However, IAMSE has utilized this uncertain time to look inward and outward and apply bold and innovative strategies to address important issues in the Association and the workplace. As an organization, we have become stronger, more visible, more supportive, and more diverse. Indeed, for IAMSE, it has been a year found.

Acknowledgements Neil Osheroff is the President of the International Association of Medical Science Educators. IAMSE takes a village to function. The author is extremely grateful for all of the hard work that Julie Hewett and her dedicated JulNet staff provide on a daily basis, and to all of the officers, board members, committee chairs, and committee members who work tirelessly on behalf of IAMSE, despite their demanding day jobs. He would also like to recognize the membership of IAMSE for all that they do to support the Association, their schools/ organizations, learners, and colleagues.

Funding The author is supported in part by Grant GM126363 from the National Institutes of Health and Merit Review award I01 Bx002198 from the United States Veterans Administration.

\section{Declarations}

Ethical Approval Not applicable.

Informed Consent Not applicable.

Conflict of Interest The author declares no competing interests.

\section{References}

1. Kelderman E. Major cost-cutting begins in response to Covid-19, with faculty and staff furloughs and pay cuts. Chronicle Higher Ed. April 18, 2020.

2. Rohan A. UAB announces temporary expense reduction strategies due to COVID-19. UAB News. May 4, 2020.

3. Friga PN. How much has covid cost colleges? $\$ 183$ billion. Chronicle Higher Ed. February 5, 2021.

4. Jean-Baptiste CO, Herring RP, Beeson WL, Dos Santos H, Banta JE. Stressful life events and social capital during the early phase of COVID-19 in the U.S. Soc Sci Humanit Open. 2020;2:100057.

5. Banerjee D, Rai M. Social isolation in Covid-19: the impact of loneliness. Int J Soc Psychiatry. 2020;66:525-7.

6. Galea S, Merchant RM, Lurie N. The mental health consequences of COVID-19 and physical distancing: the need for prevention and early intervention. JAMA Intern Med. 2020;180:817-8.

7. Vasavda C, Ho BK, Davison A. Socially distant medical education in the face of COVID-19. Med Sci Educ. 2020:1-3.

8. Wald HS. Optimizing resilience and wellbeing for healthcare professions trainees and healthcare professionals during public health crises - practical tips for an 'integrative resilience' approach. Med Teach. 2020;42:744-55.

9. Brown DL. 'It was a modern-day lynching': violent deaths reflect a brutal American legacy. https://www.nationalgeographic.com/ history/article/history-of-lynching-violent-deaths-reflect-brutalamerican-legacy. Accessed 3 Jun 2020.
10. Joseph JP, Joseph AO, Conn G, Ahsan E, Jackson R, Kinnear J. COVID-19 pandemic-medical education adaptations: the power of students, staff and technology. Med Sci Educ. 2020:1-2.

11. Rose S. Medical student education in the time of COVID-19. JAMA. 2020;323:2131-2.

12. Gibbs T. The Covid-19 pandemic: provoking thought and encouraging change. Med Teach. 2020;42:738-40.

13. Binks AP, LeClair RJ, Willey JM, Brenner JM, Pickering JD, Moore JS, Huggett KN, Everling KM, Arnott JA, Croniger CM, Zehle CH, Kranea NK, Schwartzstein RM. Changing medical education, overnight: the curricular response to COVID-19 of nine medical schools. Teach Learn Med. 2021:1-9.

14. Haras C, Calhoun A, Olson AP, Rosenberg M. Mindful medical education online. Med Sci Educ. 2021:1-10.

15. Said JT, Schwartz AW. Remote medical education: adapting Kern's curriculum design to tele-teaching. Med Sci Educ. 2021:1-8.

16. Vinkers $\mathrm{CH}$, van Amelsvoort T, Bisson JI, Branchi I, Cryan JF, Domschke K, Howes OD, Manchia M, Pinto L, de Quervain D, Schmidt MV, van der Wee NJA. Stress resilience during the coronavirus pandemic. Eur Neuropsychopharmacol. 2020;35:12-6.

17. Mosanya M. Buffering academic stress during the COVID-19 pandemic related social isolation: grit and growth mindset as protective factors against the impact of loneliness. Int $\mathbf{J}$ Appl Posit Psychol. 2020:1-16.

18. Anderson K, Looi JC. Chronic Zoom syndrome: emergence of an insidious and debilitating mental health disorder during COVID19. Australas Psychiatry. 2020;28:669.

19. Raudenska J, Steinerova V, Javurkova A, Urits I, Kaye AD, Viswanath O, Varrassi G. Occupational burnout syndrome and post-traumatic stress among healthcare professionals during the novel coronavirus disease 2019 (COVID-19) pandemic. Best Pract Res Clin Anaesthesiol. 2020;34:553-60.

20. Neary S, Van Rhee J, Roman C. The effect of the coronavirus pandemic on physician assistant educators. J Physician Assist Educ. 2020;31:121-5.

21. Pfefferbaum B, North CS. Mental health and the Covid-19 pandemic. N Engl J Med. 2020;383:510-2.

22. Chesley K. Survey reveals COVID-19's significant stress on Stanford faculty. Stanford Today. February 26, 2021.

23. Guterres A. Policy brief: the impact of COVID-19 on women. United Nations Entity for Gender Equality and the Empowerment of Women 2020.

24. Freeman J. Something old, something new: the syndemic of racism and COVID-19 and its implications for medical education. Fam Med. 2020;52:623-5.

25. Devakumar D, Shannon G, Bhopal SS, Abubakar I. Racism and discrimination in COVID-19 responses. Lancet. 2020;395:1194.

26. Johnson-Agbakwu CE, Ali NS, Oxford CM, Wingo S, Manin E, Coonrod DV. Racism, COVID-19, and health inequity in the USA: a call to action. J Racial Ethn Health Disparities. November 16, 2020.

27. Vasquez RM. The disproportional impact of COVID-19 on African Americans. Health Hum Rights. 2020;22:299-307.

28. Khazanchi R, Evans CT, Marcelin JR. Racism, not race, drives inequity across the COVID-19 continuum. JAMA Netw Open. 2020;3:e2019933.

29. Ho CP, Chong A, Narayan A, Cooke EA, Deng F, Agarwal V, DeBenedectis CM, Deitte LA, Jay AK, Kagetsu NJ. Mitigating Asian American bias and xenophobia in response to the coronavirus pandemic: how you can be an upstander. J Am Coll Radiol. 2020;17:1692-4.

30. Centers for Disease Control and Prevention. Health equity considerations and racial and ethnic minority groups. https://www. cdc.gov/coronavirus/2019-ncov/community/health-equity/raceethnicityhtml. Accessed 19 Apr 2021. 
31. Kirksey L, Tucker DL, Taylor E Jr, White Solaru KT, Modlin CS Jr. Pandemic superimposed on epidemic: Covid-19 disparities in Black Americans. J Natl Med Assoc. 2021;113:39-42.

32. Kayaoglu T. Pandemic politics: a public health crisis and a hate crisis: COVID-19 and Islamophobia. https://www.brookings.edu/ opinions/pandemic-politics-a-public-health-crisis-and-a-hate-crisiscovid-19-and-islamophobia/. Accessed 17 Jun 2020.

33. Livne S, Bejarano M. "It's important to hear a human voice," Jews under COVID-19: an oral history project. Contemp Jew. 2021:1-22.

34. Yamey G. COVID-19 has unleashed vile antisemitism. https://www. medpagetoday.com/publichealthpolicy/generalprofessionalissues/ 92622. Accessed 17 May 2021.

35. Lemieux M, Chaturvedi S, Diaz EJ, Barbar L, Bui M, Isakov D, Lee E, Lee P, Sells B, Yin TK. The time is now: student-driven implementation of social justice and anti-racism focused curricula in medical scientist training program education. FASEB Bioadv. 2021;3:439-48.

36. Fadoju D, Azap RA, Olayiwola JN. Sounding the alarm: six strategies for medical students to champion anti-racism advocacy. J Healthcare Leadership. 2021;13:1-6.

37. Lenzi RN, Korn SJ, Wallace M, Desmond NL, Labosky PA. The NIH "BEST" programs: institutional programs, the program evaluation, and early data. FASEB J. 2020;34:3570-82.

38. Osheroff N. A special message from IAMSE President, Neil Osheroff. http://www.iamse.org/a-special-message-from-iamse-president-neilosheroff/. Accessed 9 Jun 2020.

Publisher's Note Springer Nature remains neutral with regard to jurisdictional claims in published maps and institutional affiliations. 